\title{
Regulation of spermatogonial stem cell self-renewal and spermatocyte meiosis by Sertoli cell signaling
}

\author{
Su-Ren Chen and Yi-Xun Liu \\ State Key Laboratory of Reproductive Biology, Institute of Zoology, Chinese Academy of Sciences, \\ Beijing 100101, China \\ Correspondence should be addressed to Y-X Liu; Email: liuyx@ioz.ac.cn
}

\begin{abstract}
Spermatogenesis is a continuous and productive process supported by the self-renewal and differentiation of spermatogonial stem cells (SSCs), which arise from undifferentiated precursors known as gonocytes and are strictly controlled in a special 'niche' microenvironment in the seminiferous tubules. Sertoli cells, the only somatic cell type in the tubules, directly interact with SSCs to control their proliferation and differentiation through the secretion of specific factors. Spermatocyte meiosis is another key step of spermatogenesis, which is regulated by Sertoli cells on the luminal side of the blood-testis barrier through paracrine signaling. In this review, we mainly focus on the role of Sertoli cells in the regulation of SSC self-renewal and spermatocyte meiosis, with particular emphasis on paracrine and endocrine-mediated signaling pathways. Sertoli cell growth factors, such as glial cell line-derived neurotrophic factor (GDNF) and fibroblast growth factor 2 (FGF2), as well as Sertoli cell transcription factors, such as ETS variant 5 (ERM; also known as ETV5), nociceptin, neuregulin 1 (NRG1), and androgen receptor (AR), have been identified as the most important upstream factors that regulate SSC self-renewal and spermatocyte meiosis. Other transcription factors and signaling pathways (GDNF-RET-GFRA1 signaling, FGF2-MAP2K1 signaling, CXCL12-CXCR4 signaling, CCL9-CCR1 signaling, FSH-nociceptin/OPRL1, retinoic acid/FSH-NRG/ERBB4, and AR/RB-ARID4A/ARID4B) are also addressed.

Reproduction (2015) 149 R159-R167
\end{abstract}

\section{Introduction}

Spermatogenesis is precisely controlled by intrinsic gene expression and extrinsic stimuli, as shown by many lossand gain-of-function studies. Spermatogonial stem cells (SSCs) are undifferentiated spermatogonia that maintain the potential to self-renew and differentiate into committed progenitors, which sustains spermatogenesis (Kanatsu-Shinohara \& Shinohara 2013). Although selfrenewal through cell division continues through the life of the organism, little is known about how germline cells acquire and maintain their self-renewal activity. In mice, SSCs $\left(A_{\text {single }}\right)$ and committed progenitor spermatogonia $\left(A_{\text {paired }}\right.$ and $\left.A_{\text {aligned }}\right)$ are collectively described as undifferentiated A-spermatogonia based on morphological analyses (Clermont \& Bustos-Obregon 1968). These undifferentiated A-spermatogonia undergo a series of cell divisions to form differentiating spermatogonia (A1, A2, A3, A4, intermediate, and B spermatogonia) before entering meiosis (de Rooij 2001; see Fig. 1). The SSCs are defined by their ability to self-renew, and it is difficult to distinguish them from the more abundant committed progenitors based on only morphology alone. Several well-defined markers can be used to identify SSCs and other undifferentiated spermatogonia (see Fig. 1). Although PLZF (Costoya et al. 2004), SALL4 (Gassei \& Orwig 2013), and CDH1 (Tokuda et al. 2007) are expressed in all undifferentiated A-spermatogonia at all stages, GFRA1 (Grasso et al. 2012), LIN28 (Zheng et al. 2009), NANOS2 (Suzuki et al. 2009), and NGN3 (Yoshida et al. 2004) are primarily expressed in specific types of undifferentiated A-spermatogonia. In addition, ID4 and PAX7 are specific to type $\mathrm{A}_{\text {single }}$ spermatogonia (Oatley et al. 2011, Aloisio et al. 2014). NANOS3 is detectable in most undifferentiated type A-spermatogonia and differentiating type A1 spermatogonia (Suzuki et al. 2009). c-KIT, a tyrosine kinase receptor for KITL, is expressed in some type $A_{\text {aligned }}$ spermatogonia, differentiating spermatogonia, and the earliest preleptotene spermatocytes (Yoshinaga et al. 1991). SOHLH1 and SOHLH2 are expressed in both c-KIT-negative and c-KITpositive spermatogonia, with the exception of GFRA $1^{+}$ spermatogonia (Suzuki et al. 2012). PLZF is the first transcription factor to be identified as being involved in SSC self-renewal. SALL4 functions by removing PLZF from its cognate targets (e.g. c-KIT). Thus, the competition between PLZF and SALL4 is an important topic of investigation. It has been recently shown by Liao et al. (2014) that reduced levels of PLZF in Dnmt3l-knockout Thy $1^{+}$cells results in the releases of the PLZF antagonist 


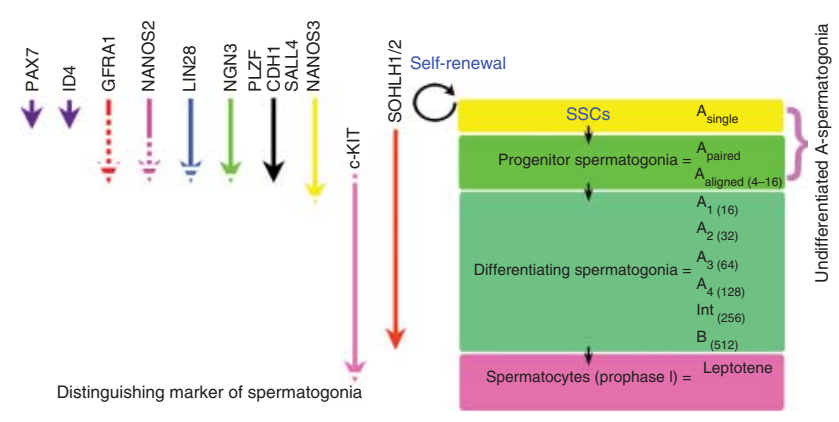

Figure 1 Characteristics of mammalian spermatogonial development and protein markers of SSCs. Whether SSC division is a symmetric or asymmetric process in mammals remains a topic of debate. Regardless of division pathways, SSCs undergo either self-renewal, to maintain a pool of SSCs, or differentiation, committing to differentiating into spermatogonia and then entering meiosis. A number of well-defined markers of SSCs in the mammalian germline have been summarized, of which ID4 and PAX7 selectively mark type $\mathrm{A}_{\text {single }}$ spermatogonia. Undifferentiated type A-spermatogonia may be basically classified into three categories: GFRA ${ }^{+}{ }^{+} \mathrm{NANOS} 2^{+} \mathrm{LIN} 28^{-} \mathrm{NGN} 3^{-}$, GFRA ${ }^{+}$ NANOS2 ${ }^{+} \mathrm{LIN}_{28}{ }^{+} \mathrm{NGN}^{-}{ }^{-}$, and GFRA $1^{-} \mathrm{NANOS} 2^{-} \mathrm{LIN}_{28}{ }^{-} \mathrm{NGN} 3^{+}$ (Suzuki et al. 2009). The dashed and colored arrows indicate the period of expression. The succession of the various types of germ cells during the early stage of mouse spermatogenesis is represented in the image: $A_{\text {single, }}$ a single spermatogonia; $A_{\text {paired, }}$ a paired spermatogonia; $A_{\text {aligned, }}$ an aligned spermatogonia; $A_{1}, A_{2}, A_{3}, A_{4}$, types $A_{1}-A_{4}$ spermatogonia; Int, intermediate spermatogonia; $B$, type $B$ spermatogonia.

SALL4, which is associated with maintaining the delicate balance of cycling and quiescent SSCs/progenitor cells. Further study is required to investigate whether SALL4 ${ }^{+}$/ $\mathrm{PLZF}^{-} \mathrm{A}_{\text {single }}$ and $\mathrm{A}_{\text {paired }}$ spermatogonia are destined to differentiate. The human ortholog of the mouse SSC maintenance factor PLZF is expressed in spermatogonia, and its biallelic loss in humans is associated with genital hypoplasia (Fischer et al. 2008). To our knowledge, PAX7 is the only protein known to be expressed in SSCs in a variety of mammals, including human. Further studies are needed to identify additional markers of human SSCs and other undifferentiated spermatogonia. It is also important to test the classic studies of SSCs through spermatogonial transplantation techniques and other functional SSCs assays.

Meiosis is essential for the production of haploid gametes from spermatocytes and maintaining genome integrity (Li et al. 2005). Prophase of meiosis $\mathrm{I}$ is unique in that it is elongated and further broken down into leptotene, zygotene, pachytene, diplotene, and diakinesis. During these substages of prophase I, DNA double-strand breaks, alignment and synapsis of homologues, and crossover formation ensure homologous recombination between non-sister chromatids (review in Pawlowski \& Cande (2005)). Meiosis is precisely controlled by intrinsic and extrinsic factors, as shown in numerous gene knockout studies.

Scrotal hypothermia is essential for normal spermatogenesis (Paul et al. 2009); therefore, it is important to understand why spermatogenesis is negatively affected by heat. Our previous studies demonstrated that temporal heat stress in the testes resulted in a dramatic reduction in the expression of upstream factors, such as androgen receptor (AR), Wilms' tumor gene 1 (WT1), and liver receptor homolog 1 (LHR1) in monkey (Zhang et al. 2006, Guo et al. 2007, Chen et al. 2008), rat (Guo et al. 2007), and mouse (Cai et al. 2011); however, these effects were reversible. The reversible dedifferentiation of Sertoli cells is followed by a temporary reversible disruption of the blood-testis barrier (BTB), which leads to dramatic germ cell apoptosis in the testis (Lue et al. 2006). Importantly, heat-induced changes in Sertoli cells and the failed spermatogenesis were found to recover over time. Upstream factors may act as transcription factors to regulate the reversible change in Sertoli cell differentiation and the process of spermatogenesis via BTB-associated proteins. For example, when the AR was over-expressed, the heat-induced downregulation of BTB-associated proteins was rescued. AR knockdown by RNA interference (RNAi) or treatment with an $A R$ antagonist (flutamide) inhibited the recovery of BTBassociated proteins. Furthermore, the co-localization and interactions of components of partitioning-defective protein 6 (PAR6)-PAR3-aPKC-Cdc42 polarity complex components were disrupted in both AR-knockdown and heat-treated Sertoli cells (see Fig. 2; Li et al. 2013). Our study suggests that a small number of undifferentiated spermatogonia survival in the disrupted niche after heat treatment and the SSC niche and BTB are re-established after the heat stress is withdrawn. Sertoli cells, which are the principal contributors to the SSC niche and the BTB structure, play a central role in both the disruption and recovery process. Absalan et al. (2011) demonstrated that spermatogonia isolated from bilateral cryptorchid mice have the ability to regenerate spermatogenesis. Based on these findings, we support the notion that spermatogenesis is regulated by a complex paracrine and endocrine system within a structurally wellorganized tissue. Central to this system are the Sertoli cells, which provide nutrient and structural support for the differentiating germ cells.

In this review, we summarize findings regarding the paracrine regulation of SSC self-renewal and spermatocyte meiosis by Sertoli cells. The well-defined glial cell line-derived neurotrophic factor (GDNF) is a soluble factor that is secreted by Sertoli cells and influences the self-renewal of SSCs while inhibiting their differentiation (Meng et al. 2000). The generation and characterization of male total and conditional AR knockout mice from different laboratories demonstrate the exceeding necessity of Sertoli cell-expressed AR signaling for meiosis (review in Wang et al. (2009)). Significant progress has recently been made by us and others in exploring the effects of Sertoli cells on the regulation of SSC selfrenewal and spermatocyte meiosis. Several authoritative reviews have recently been presented that describe the 


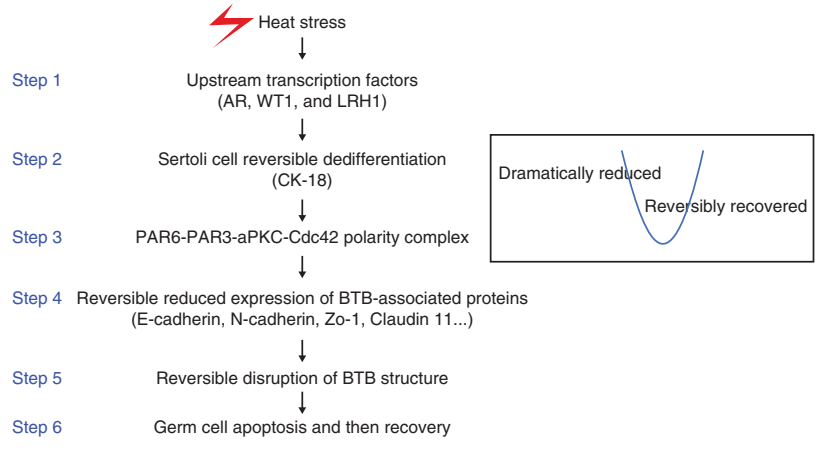

Figure 2 Diagram summarizing the hypothesized mechanism underlying the reversible effects of scrotal heat stress on Sertoli cell function. The disruption of spermatogenesis and its reversible recovery can be divided into six steps (Li et al. 2013). Heat stress perturbs the BTB structure, which may be mediated via effects on upstream transcription factors (WT1, AR, and LHR1) and the PAR3/PAR6 polarity complex within Sertoli cells and the subsequent effects on BTB-associated proteins between Sertoli cells. Thus, Sertoli cells are considered to be the main cellular mediators of the effects of heat stress on spermatogenesis.

transcriptional regulation of spermatogonial differentiation and spermatocyte meiosis by intrinsic factors (Rossi \& Dolci 2013, Hai et al. 2014, Song \& Wilkinson 2014). Thus, in this review, we focus on Sertoli cellcontrolled paracrine signaling during early stages of spermatogenesis.

\section{GDNF signaling}

Niche factor GDNF, secreted by Sertoli cells, is a welldefined paracrine factor that promotes SSC self-renewal and maintenance, as shown both in vivo and in vitro. Gndf $^{-1-}$ mice die at birth with renal and neuronal abnormalities (Meng et al. 2000). Gdnf ${ }^{+/-}$mice present an exhausted SSC pool and progressive germ cell loss, whereas mice overexpressing GDNF show an accumulation of undifferentiated spermatogonia (Meng et al. 2000). Subsequent studies have described the long-term culture of SSCs based on this finding (Kubota et al. 2004, Hofmann et al. 2005). This culture system allows a large number SSCs to be collected; thus, the investigation of SSCs at the molecular level is now possible using these techniques. Human and mouse spermatogonia use the same extrinsic factor, GDNF, for their maintenance and growth in vitro (Wu et al. 2009). GDNF signaling acts via the RET tyrosine kinase present on undifferentiated type A-spermatogonia (Naughton et al. 2006) and requires a ligand-specific co-receptor GFRA1 (Jing et al. 1996) to promote spermatogonial self-renewal in mice (see Fig. 3). Studies in RET Y1062F knockin mice suggest that GDNF-RET signaling is essential for the self-renewal of SSCs via tyrosine 1062 (Jijiwa et al. 2008).

Further studies have been undertaken to identify the signaling pathways through which these molecules function. The molecular machinery of the GDNF signaling pathway in SSC self-renewal has been investigated in in vitro SSC culture experiments with specific inhibitors. Using this approach, it was shown that the PI3K/AKT-dependent pathway (Lee et al. 2007) or the SRC family kinase (SFK) pathway (Oatley et al. 2007) mediate GDNF function in SSCs. A microarray analysis of cultured Thy $1^{+}$SSCs was conducted to identify GDNF-inducible genes in SSCs, which show decreased expression upon GNDF withdrawal and increased expression upon GDNF replacement (Oatley et al. 2006). The transcription factors $B$ cell CLL/ lymphoma 6 member B (BCL6B), ETS variant 5 (ERM; also known as ETV5), DNA-binding protein 4 (ID4), LIM homeobox 1 (LHX1), BRACHYURY (T), and POU class 3 homeobox 1 (POU3F1) were reported to be essential for SSC self-renewal (Oatley et al. 2006).

$\mathrm{BCL} 6 \mathrm{~B}$ has been shown to be important for maintenance of the self-renewal of SSCs in vitro based on results obtained using siRNA; the degeneration of spermatogenesis or a Sertoli cell-only phenotype was observed in the Bcl6b-null testes (Oatley et al. 2006). ETV5 was

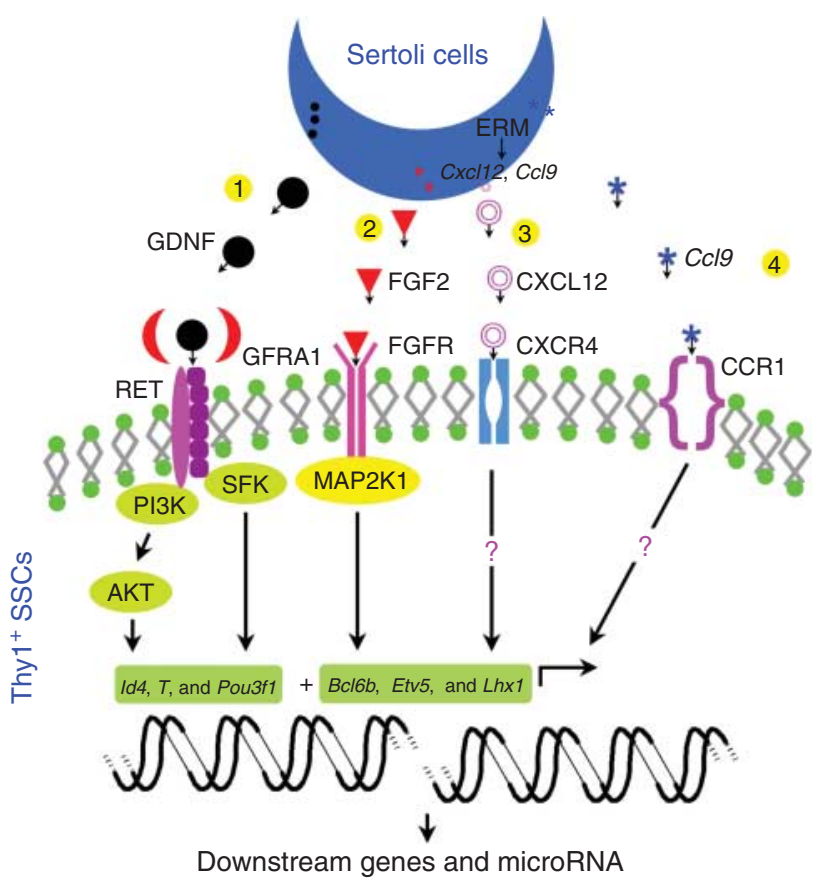

Figure 3 Current understanding of signaling pathways regulating SSC self-renewal in mouse testes. (1) GDNF/RET/GFRA1 activate PI3K/AKT and SFK intercellular signaling mechanisms, influencing transcription factors that have been shown to promote SSC self-renewal, such as BCL6B, ETV5, LHX1, ID4, T, and POU3F1. (2) FGF2 relies on MAP2K1 activation to drive SSC self-renewal via the upregulation of the Etv5, $B c 16 b$, and $L h x 1$ genes. (3) Sertoli cell-secreted CXCL12 signals via the CXCR4 receptor present on SSCs to regulate self-renewal through an undefined intercellular signaling pathway. (4) Ccl9 encodes a chemokine that facilitates Sertoli cell chemoattraction of undifferentiated type A-spermatogonia through its receptor CCR1, which is present on SSCs. ERM is predominantly expressed within Sertoli cells and promotes SSC self-renewal via the regulation of CXCL12/CXCR4 and CCL9/CCR1 signaling. 
expressed both in Sertoli cells (Chen et al. 2005) and in SSCs (Oatley et al. 2007, Tyagi et al. 2009). Etv5-null germ cells fail to initiate spermatogenesis after transplantation into the testes of $W / W^{v}$ mice. Specifically, a positive feedback loop involving ETV5 and GDNF/RET/ GFRA1 regulates SSC self-renewal (Tyagi et al. 2009). Interestingly, a recent study has suggested that ETV5 directly activates the expression of microRNA-21 to regulate the self-renewal of mouse SSCs (Niu et al. 2011). MicroRNA signaling in testicular Sertoli and germ cells may comprise another level of regulation of the SSC niche (reviewed in van den Driesche et al. (2014)). siRNA-mediated reduction in ID4 abolished the ability of SSCs to expand in vitro, and Id4-mutant mice exhibit progressive loss of the undifferentiated spermatogonial population (Oatley et al. 2011). Similarly, knockdown of LHX1 in cultured SSCs reduced their ability to form colonies in functional SSC transplantation assays (Oatley et al. 2007). Functional transplantation of SSCs following the silencing of $\mathrm{T}$ significantly reduces the number of donor cell-derived colonies formed within the testes of busulfan-treated recipient mice (Wu et al. 2011). In addition, transient depletion of POU3F1 reduces the number of SSCs via the induction of apoptosis, and transplantation analyses revealed impaired SSC maintenance (Wu et al. 2010).

To thoroughly explore the downstream gene network, microarray analysis of Thy $1^{+}$spermatogonial cell cultures depleted of ETV5, BCL6B, and POU3F1 by RNAi showed that several genes and microRNA integral for SSC self-renewal are regulated by these upstream transcriptional factors (reviewed in Song \& Wilkinson (2014)). The functional interactions and feedback loops of GDNF signaling with other SSC self-renewal regulators will be the focus of future studies and will be useful for dissecting this unique process. Human orthologs of mouse SSC maintenance genes, such as RET, GFRA1, $E T V 5, I D 4$, and $B C L 6 B$, are highly enriched in human spermatogonia relative to somatic cells (Wu et al. 2009, Sachs et al. 2014). Whether these genes contribute to SSCs self-renewal in humans will require further investigation via in vitro studies.

Recent studies have concentrated on the impact of GDNF on SSCs rather than molecular control of GDNF expression in Sertoli cells. Most recently, an interesting study has characterized the promoter region of the mouse Gdnf gene in Sertoli cells, and deletion analysis revealed the involvement of the three CRE sites in the basal and cAMP-induced expression of Gdnf in Sertoli cells (Lamberti \& Vicini 2014).

\section{Fibroblast growth factor 2-MAP2K1/AKT signaling}

Fibroblast growth factor 2 (FGF2, also known as basic FGF (bFGF)) is expressed and secreted by mammalian Sertoli cells and stimulates SSC self-renewal. In vitro, supplementation of FGF2 in combination with GDNF allowed for long-term self-renewing expansion of SSCs (Kubota et al. 2004). In humans, FGF2 treatment increased the diameters of SSC colonies (Mirzapour et al. 2012). Although the role of the GDNF signaling pathway has been described in SSCs, little is known about the involvement of FGF2. A recent study has demonstrated that FGF2 relies on MAP2K1 activation to drive SSC self-renewal via upregulation of Etv5, Bcl6b, and $L h x 1$ genes using a mouse germline stem (GS) cell culture system that allows for in vitro expansion of SSCs (Ishii et al. 2012; see Fig. 3). GS cells with activated MAP2K1 proliferate in the presence of GDNF, which indicates that MAP2K1 can substitute for FGF2. Thus, PI3K/AKT, SFK, and MAP2K1 are critical regulators of SSC self-renewal. Interestingly, Lee et al. (2009) used a SSC transplantation assay to show that the activation of H-RAS is sufficient to induce SSC self-renewal and that $\mathrm{PI} 3 \mathrm{~K} / \mathrm{AKT}$ and MAP2K1 are RAS effectors.

A subsequent study indicated that FGF2 may regulate mouse SSC proliferation and stem cell activity in vitro via autocrine phosphorylation of AKT and ERK1/2 pathway (Zhang et al. 2012). Conditional knockout of the Fgf2 gene in postnatal Sertoli cells and SSCs could help to elucidate the essential role of FGF2 in SSC self-renewal in vivo.

\section{CXCL12-CXCR4 signaling}

Cxcl12 encodes a chemokine that is expressed and secreted by Sertoli cells and binds to the CXCR4 receptor on SSCs to regulate self-renewal and maintenance (see Fig. 3). The reduction of CXCR4 signaling in primary cultures of undifferentiated mouse spermatogonia by treatment with a CXCR4-specific inhibitor and the injection of CXCL12-blocking-antibody results in SSC loss, and the inhibition of CXCR4 signaling in testes of adult mice by injection of CXCR4-specific inhibitor impairs SSC maintenance, leading to loss of the germline (Yang et al. 2013). Both GDNF and FGF2 regulate the expression of Cxcr4 mRNA in Thy $1^{+}$spermatogonial cell cultures. Microarray profiling of gene expression revealed that the disruption of CXCL12-CXCR4 signaling leads to a significant decrease in the abundance of the Fgf2 transcript (Yang et al. 2013), suggesting that CXCL12, FGF2, and GNDF form a cooperative network that influences SSC self-renewal. Moreover, CXCR4 participates in both primordial germ cell homing during embryogenesis and SSC homing to the germline niche in postnatal testes (Ara et al. 2003, Kanatsu-Shinohara et al. 2012). Sertoli cell-specific Sin3a deletion resulted in the formation of few undifferentiated spermatogonia. Chemokine CXCL12 and its receptor CXCR4 are not detected in neonatal Sertoli cell-specific Sin3a-knockout testes (Payne et al. 2010), indicating that CXCL12CXCR4 signaling influences the establishment of the SSC niche.

Mclver et al. (2013) observed that the CXCL12 and its receptor CXCR4 are expressed in the human testis, 
which led us speculate that CXCL12-CXCR4 signaling may be involved in human SSC biology.

\section{ERM-chemokine signaling}

Chen et al. (2005) demonstrated that ERM is expressed exclusively within Sertoli cells and is required for SSC self-renewal. Mice with targeted disruption of the ERM cannot maintain SSC self-renewal without a disruption in normal spermatogenic differentiation; thus, progressive germ cell depletion and Sertoli-cell-only syndrome were observed (Chen et al. 2005). Microarray analysis of purified wild type (WT) and $\mathrm{Erm}^{-1-}$ Sertoli cells indicates that GDNF expression was unchanged and that several chemokine genes, $\mathrm{CxCl} 12, \mathrm{CxCl} 5$, and $\mathrm{CCl} 7$, were significantly reduced in $\mathrm{Erm}^{-1-}$ Sertoli cells, suggesting that these genes play a role in regulating the SSC niche (Chen et al. 2005). Simon et al. (2010) reported that recombinant CCL9 restored the chemoattractive ability of $\mathrm{Erm}^{-1-}$ Sertoli cells, suggesting that CCL9/CCR1 may be a direct target of ERM. Transient siRNA oligonucleotides targeting ERM in mouse SSC cultures further confirmed that ERM is a regulator of CxCr4 (Wu et al. 2011). Therefore, changes in chemokine production and the consequent decreases in chemoattraction by $\mathrm{Erm}^{-1-}$ Sertoli cells result in SSC loss in Erm ${ }^{-1-}$ mice (see Fig. 3). ERM appears to be one of the few transcription factors expressed by Sertoli cells that control SSC self-renewal through either CXCL12/CXCR4 or CCL9/CCR1 signaling. The intracellular mechanisms of CXCL12/CXCR4 and CCL9/CCR1 signaling require further investigation.

\section{Role of follicle-stimulating hormone-nociceptin/ OPRL1 signaling in meiosis}

Total serum immunoactive follicle-stimulating hormone (FSH) levels increase in mice beginning at 8 days postpartum onward (Barakat et al. 2008). FSH directly activates the intracellular signaling pathway and leads to the secretion of paracrine factors that indirectly promote spermatogenesis. Recently, the paracrine factors have involved in the signaling between Sertoli cells and germ cells to mediate the effect of FSH on spermatocyte meiosis have been investigated. Nociceptin was found to be upregulated by a surge in FSH levels in mouse Sertoli cells (Eto et al. 2012), and the nociceptin receptor OPRL1 is exclusively expressed on the plasma membrane of spermatocytes (Eto et al. 2013). Nociceptin induces and maintains REC8 phosphorylation, which is responsible for meiotic chromosome dynamics in spermatocytes during meiosis (Lee et al. 2003, Eto et al. 2013; see Fig. 4). Although the mechanism by which nociceptin stimulates REC8 phosphorylation in spermatocytes remains unclear, nociceptin/OPRL1 is a novel extrinsic signaling pathway that plays a crucial role in the progression of meiosis.

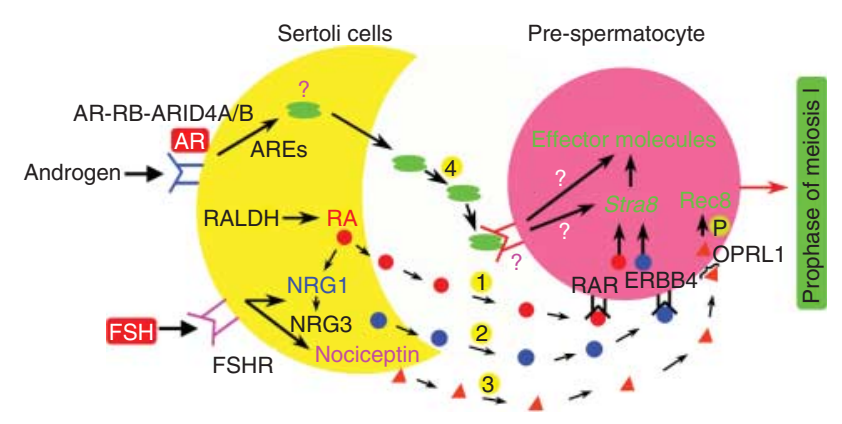

Figure 4 Schematic diagram of the Sertoli cell-controlled paracrine mechanisms acting on meiosis. (1) RA is synthesized by retinaldehyde dehydrogenases (RALDH) within the Sertoli cells, and it binds to nuclear RA receptors (RAR), which stimulates Stra8 expression in prespermatocytes. (2) FSH and RA induce spermatocyte meiosis indirectly through Sertoli cells when NRG1 and NRG3 are upregulated and bind to their receptor ERBB4 in pre-spermatocytes. (3) OPRL1 localizes to the surface of spermatocytes and responds to nociceptin, which is expressed and secreted by Sertoli cells and functions in spermatocytes to induce REC8 phosphorylation and subsequent meiotic chromosome dynamics. (4) Androgen-AR binds to the ARE on androgen-responsive genes to regulate the expression of unknown signaling factors that may interact with specific receptors in spermatocytes to trigger the expression of Stra8 gene and/or effector molecules. ARID4A/B also functionally links the AR and RB pathways in meiotic regulation.

\section{Effect of retinoic acid/FSH-neuregulin signaling in meiosis}

In murine juvenile testes, Sertoli cell-synthesized retinoic acid (RA) serves as a fundamentally positive regulator in the commitment of spermatocytes to meiosis and it also regulates progression of the early stages of meiotic prophase via the stimulated RA gene 8 (Stra8) (Mark et al. 2008). However, the molecular pathway by which RA induces meiosis requires further elucidation. Neuregulin 1 (NRG1), a member of the epidermal growth factor family, has only been found to be present in Sertoli cells, and its receptor, ERBB4, localizes to the surface of germ cells (Falls 2003, Zhang et al. 2011). Recently, Zhang et al. (2011) have demonstrated that RA and FSH act on Sertoli cells to promote the expression of NRG1 and NRG3, directly inducing meiosis in pre-spermatocytes, based on the analyses of $\mathrm{Nrg} 1^{\mathrm{Ser}-/-}$ mutant mice and of re-aggregated cultures consisting of spermatogonia and Sertoli cells (see Fig. 4). However, the mechanisms by which RA promotes $\mathrm{Nrg} 1$ and $\mathrm{Nrg3}$ mRNA expression in Sertoli cells and how NRG1/3 stimulates Stra8 gene expression remain to be elucidated.

\section{The function of androgen-AR signaling in meiosis}

Genetic studies in the mouse demonstrate that meiosis is one of the most important processes controlled by androgen-AR signaling. Currently, more than 1029 different AR missense mutations have been reported, contributing to $\sim 2 \%$ of cases of non-specific male infertility (Gottlieb et al. 2012). When bound by 
androgen, cytoplasmic AR in Sertoli cells quickly translocates to the nucleus and binds to the androgen response elements (ARE) on androgen-responsive genes (Zhou et al. 2002). In addition to Sertoli cells, testicular $A R$ is also expressed in Leydig cells and peritubular myoid (PM) cells. In the absence of AR in Sertoli cells in mice, spermatogenesis does not progress beyond the pachytene or diplotene stages of meiosis (Chang et al. 2004, De Gendt et al. 2004), while the deletion of the $A r$ gene in mouse germ cells does not affect spermatogenesis or male fertility (Tsai et al. 2006). Germ cells themselves lack AR function, but they depend on androgen to progress beyond meiosis, indicating that androgens regulate meiosis indirectly by acting on Sertoli cells. Therefore, the molecular mechanism by which Sertoli cells transduce the androgenic stimulus to germ cells is of great significance and should be addressed.

Retinoblastoma (RB) has been reported to interact with $A R$ and functions as a co-activator to induce $A R$ transcriptional activity. A recent study has identified several AR- and RB-responsive genes acting as downstream targets of ARID4A and ARID4B (Wu et al. 2013). ARID4A and ARID4B are expressed mainly in Sertoli cells. An investigation of germ cell development in Arid $4 a^{-1-}$ Arid $4 b^{+/-}$mice revealed spermatogenic arrest in the meiotic spermatocytes and post-meiotic haploid spermatids (Wu et al. 2013). This study thus indicates that ARID4A/B functionally links the $A R$ and RB pathways in the regulation of spermatogenic meiosis. The signaling pathways of spermatocyte meiosis regulated by Sertoli cells are illustrated in Fig. 4 .

\section{Perspectives and concluding remarks}

In summary, we have systematically addressed the roles of Sertoli cell-derived soluble factors and Sertoli cellexpressed transcription factors in the regulation of SSC self-renewal and spermatocyte meiosis. ID4 and PAX7 are two proteins known to be expressed in $A_{\text {single }}$ spermatogonia (SSCs), and Id4-GFP is a candidate reporter line that preferentially labels SSCs (Oatley et al. 2011). Special attention should be paid to determine whether the cessation of spermatogenesis is accompanied by a deficiency in SSCs. Analyses of cells that retain the label long-term may be a useful approach for detecting an SSC defect. In the future, it will be crucial to identify SSC-specific markers and reporter lines that preferentially label SSCs to distinguish between SSC and spermatogonial progenitors.

Microarray analysis can be used to identify the genes and microRNA that are regulated by GDNF-inducible transcription factors involved in SSC self-renewal, such as BCL6B, ETV5, ID4, LHX1, T, and POU3F1 (review in Song \& Wilkinson (2014)). Similar studies suggest that GDNF and FGF2 share common target genes. However, microarray data cannot distinguish between direct and indirect targets, and further analysis of the transcriptional regulation is required. Very recently, Kanatsu-Shinohara et al., have reported that F-box and WD-40 domain protein 7 (FBXW7) play an important role in negatively regulating self-renewal. To our knowledge, this is the first report of increased SSC activity in knockout mice. Investigation of other negative regulators that may counteract self-renewal signals will deepen our knowledge of SSC biology (Kanatsu-Shinohara et al. 2014).

Human SSCs share some but not all phenotypes with rodent SSCs, and long-term culture of SSCs has not yet been achieved in humans (Guo et al. 2014). Most of the knowledge related to the paracrine regulation of SSC fate has been derived from rodents. To our knowledge, no transcription factors have yet been identified that have roles in either SSC self-renewal or differentiation in humans. Because of the significant differences between rodent and human spermatogonia, human orthologs of mouse transcription factors that control SSC events in mice have yet to be further investigated. It will also very important to explore the regulation of human SSC selfrenewal by Sertoli paracrine signaling to provide insights into male infertility.

Stem cell niches are formed on the basis of both architectural support and external stimuli produced by niche cells. In this study, we summarize the recent understanding of Sertoli paracrine regulation of SSC function. However, contributions from other somatic cell populations surrounding the seminiferous tubules, such as PM cells, interstitial Leydig cells, and blood vessels, are also possible. Yoshida et al. (2007) demonstrated a vascular and interstitial tissue-associated niche for undifferentiated spermatogonia in the mouse. However, the role of the vasculature by layers of appears to be indirect because spermatogonia are separated from the vasculature by the layers of basement membrane. Colony-stimulating factor 1 (CSF1) has been identified as an extrinsic stimulator of SSC self-renewal that implicates Leydig and selects PM cells as contributors of the testicular stem cell niche in mammals (Oatley et al. 2009). However, whether in vivo SSCs express the CSF1 receptor remains to be investigated. A recent study has reported that testosteronedependent regulation of GDNF expression in PM cells has a significant influence on the microenvironment of the niche and SSC maintenance (Chen et al. 2014). Future studies should investigate how the activity of the SSC niche is regulated by interstitial tissues, hormones, spermatogenic cycles, and aging. Although in vivo analysis of the niche is difficult owing to the three-dimensional structure of seminiferous tubules, in vitro reconstitution of the SSC niche has recently become possible (Kanatsu-Shinohara et al. 2012). Characterization of the in vitro reconstituted niche will provide a unique tool to study the interactions between SSCs and their microenvironment.

Azoospermia has been observed in $10-15 \%$ of cases of male infertility and in $1 \%$ of the general population, and non-obstructive azoospermia has been diagnosed in $60 \%$ of azoospermic men. The ability of generating 
mature and functional male gametes from SSCs could enable us to understand the precise etiology of male infertility and offer an invaluable source of autologous male gametes for treating male infertility in azoospermic patients. From this viewpoint, the development of in vitro differentiation methods will be the next important step. In addition, spermatogonia transplantation is inefficient in nonrodent animals because of the difficulties related to preparing the recipients and the low concentrations of SSCs. Thus, the development of in vitro differentiation approaches will overcome these problems. Currently, considerable progress has been made in generating male germ cells, including spermatogonia, spermatocytes, and spermatids, from various types of stem cells (reviewed in Hou et al. (2014)). Of note, haploid spermatids were generated in human SSCs from cryptorchidism patients by treatment with RA and stem cell factor (Yang et al. 2014). We developed an efficient system by co-culturing GFR $\alpha 1$-positive gonocytes/undifferentiated spermatogonia with autologous testicular cells isolated from mice around 2.5 days old, creating a functional 'testis' in vitro which undergoes spermatogenesis to produce haploid sperm (Y Zhang, SL Deng, SR Chen, CY Cheng and YX Liu, unpublished data). This culture system will provide an invaluable source of autologous male gametes for treating male infertility in azoospermic patients.

Other candidate molecules in Sertoli cells that may be involved in SSC self-renewal and meiosis include WNT5a, doublesex and MAB 3-related transcription factor 1 (DMRT1), and WT1. Yeh et al. (2011) have identified WNT5a as an extrinsic regulator of SSC selfrenewal (Yeh et al. 2011). WNT5a was shown to be present in the Sertoli cells of the mouse testis, and the WNT5a receptor was detected on the SSC cell surface. It remains unknown how WNT5a influences SSCs. Germ cells in Sertoli cell-specific knockout of DMRT1 testes efficiently enter meiosis, but the majority exhibit arrest at or before the pachytene stage (Kim et al. 2007). In our study, mice with a deletion of Wt1 exhibited clear meiotic arrest and undifferentiated spermatogonia accumulation in the seminiferous tubules (Zheng et al. 2014). However, it remains to be defined how DMRT1 and $\mathrm{WT} 1$ regulate meiosis in a paracrine manner.

The results of studies carried out in Sertoli-Ar knockout mice clearly demonstrate that AR function in Sertoli cells is essential for the maintenance of fully competent Sertoli cell functions that support the completion of meiosis I during spermatogenesis. The next study will focus on which signaling events mediate AR function in spermatogenesis. Genetic screening of infertile males has revealed many $A R$ mutations that are associated with male infertility. The restoration of spermatogenesis in Ar-knockout mice via alteration of candidate paracrine signals will be a powerful tool for demonstrating male infertility caused by $A R$ mutation.
We expect that further investigation of Sertoli cell-specific genes and cell signaling in the regulation of self-renewal and spermatocyte meiosis in SSCs will yield useful insights into the treatment of male infertility and the development of safe and effective male contraception.

\section{Declaration of interest}

The authors declare that there is no conflict of interest that could be perceived as prejudicing the impartiality of the review.

\section{Funding}

Supported by the Major Research Plan '973' Project (2011CB944302 and 2012CB944702), the National Technology Support Project (2012DAI131B08), and the National Natural Science Foundation of China $(31471352,31471400$, $31171380,31071018,31071271$, and 81270662).

\section{References}

Absalan F, Movahedin M \& Mowla SJ 2011 Spermatogonial stem cell transplantation and subsequent orchidopexy in the bilateral cryptorchid mouse model. Cell Journal 13 143-148.

Aloisio GM, Nakada Y, Saatcioglu HD, Pena CG, Baker MD, Tarnawa ED, Mukherjee J, Manjunath H, Bugde A, Sengupta AL et al. 2014 PAX7 expression defines germline stem cells in the adult testis. Journal of Clinical Investigation 124 3929-3944. (doi:10.1172/JCI75943)

Ara T, Nakamura Y, Egawa T, Sugiyama T, Abe K, Kishimoto T, Matsui Y \& Nagasawa T 2003 Impaired colonization of the gonads by primordial germ cells in mice lacking a chemokine, stromal cell-derived factor-1 (SDF-1). PNAS 100 5319-5323. (doi:10.1073/pnas.0730719100)

Barakat B, O'Connor AE, Gold E, de Kretser DM \& Loveland KL 2008 Inhibin, activin, follistatin and FSH serum levels and testicular production are highly modulated during the first spermatogenic wave in mice. Reproduction 136 345-359. (doi:10.1530/REP-08-0140)

Cai H, Ren Y, Li XX, Yang JL, Zhang CP, Chen M, Fan CH, Hu XQ, Hu ZY, Gao F et al. 2011 Scrotal heat stress causes a transient alteration in tight junctions and induction of TGF- $\beta$ expression. International Journal of Andrology 34 352-362. (doi:10.1111/j.1365-2605.2010.01089.x)

Chang C, Chen YT, Yeh SD, Xu Q, Wang RS, Guillou F, Lardy H \& Yeh S 2004 Infertility with defective spermatogenesis and hypotestosteronemia in male mice lacking the androgen receptor in Sertoli cells. PNAS 101 6876-6881. (doi:10.1073/pnas.0307306101)

Chen C, Ouyang W, Grigura V, Zhou Q, Carnes K, Lim H, Zhao GQ, Arber S, Kurpios N, Murphy TL et al. 2005 ERM is required for transcriptional control of the spermatogonial stem cell niche. Nature 436 1030-1034. (doi:10.1038/nature03894)

Chen M, Cai H, Yang JL, Lu CL, Liu T, Yang W, Guo J, Hu XQ, Fan CH, Hu ZY et al. 2008 Effect of heat stress on expression of junctionassociated molecules and upstream factors androgen receptor and Wilms' tumor 1 in monkey Sertoli cells. Endocrinology 149 4871-4882. (doi:10.1210/en.2007-1093)

Chen LY, Brown PR, Willis WB \& Eddy EM 2014 Peritubular myoid cells participate in male mouse spermatogonial stem cell maintenance. Endocrinology 155 4964-4974. (doi:10.1210/en.2014-1406)

Clermont Y \& Bustos-Obregon E 1968 Re-examination of spermatogonial renewal in the rat by means of seminiferous tubules mounted "in toto". American Journal of Anatomy 122 237-247. (doi:10.1002/aja. 1001220205)

Costoya JA, Hobbs RM, Barna M, Cattoretti G, Manova K, Sukhwani M, Orwig KE, Wolgemuth DJ \& Pandolfi PP 2004 Essential role of Plzf in maintenance of spermatogonial stem cells. Nature Genetics 36 653-659. (doi:10.1038/ng1367) 
De Gendt K, Swinnen JV, Saunders PT, Schoonjans L, Dewerchin M, Devos A, Tan K, Atanassova N, Claessens F, Lecureuil C et al. 2004 A Sertoli cell-selective knockout of the androgen receptor causes spermatogenic arrest in meiosis. PNAS 101 1327-1332. (doi:10.1073/ pnas.0308114100)

van den Driesche S, Sharpe RM, Saunders PT \& Mitchell RT 2014 Regulation of the germ stem cell niche as the foundation for adult spermatogenesis: a role for miRNAs? Seminars in Cell \& Developmental Biology 29 76-83. (doi:10.1016/j.semcdb.2014.04.006)

Eto K, Shiotsuki M, Sakai T \& Abe S 2012 Nociceptin is upregulated by FSH signaling in Sertoli cells in murine testes. Biochemical and Biophysical Research Communications 421 678-683. (doi:10.1016/j.bbrc.2012.04.061)

Eto K, Shiotsuki M \& Abe S 2013 Nociceptin induces Rec8 phosphorylation and meiosis in postnatal murine testes. Endocrinology 154 2891-2899. (doi:10.1210/en.2012-1977)

Falls DL 2003 Neuregulins: functions, forms, and signaling strategies. Experimental Cell Research 284 14-30. (doi:10.1016/S0014-4827 (02)00102-7)

Fischer S, Kohlhase J, Bohm D, Schweiger B, Hoffmann D, Heitmann M, Horsthemke B \& Wieczorek D 2008 Biallelic loss of function of the promyelocytic leukaemia zinc finger (PLZF) gene causes severe skeletal defects and genital hypoplasia. Journal of Medical Genetics 45 731-737. (doi:10.1136/jmg.2008.059451)

Gassei K \& Orwig KE 2013 SALL4 expression in gonocytes and spermatogonial clones of postnatal mouse testes. PLOS ONE 8 e53976. (doi:10.1371/journal.pone.0053976)

Gottlieb B, Beitel LK, Nadarajah A, Paliouras M \& Trifiro M 2012 The androgen receptor gene mutations database: 2012 update. Human Mutation 33 887-894. (doi:10.1002/humu.22046)

Grasso M, Fuso A, Dovere L, de Rooij DG, Stefanini M, Boitani C \& Vicini E 2012 Distribution of GFRA1-expressing spermatogonia in adult mouse testis. Reproduction 143 325-332. (doi:10.1530/REP-11-0385)

Guo J, Tao SX, Chen M, Shi YQ, Zhang ZQ, Li YC, Zhang XS, Hu ZY \& Liu YX 2007 Heat treatment induces liver receptor homolog-1 expression in monkey and rat Sertoli cells. Endocrinology 148 1255-1265. (doi:10. 1210/en.2006-1004)

Guo Y, Hai Y, Gong Y, Li Z \& He Z 2014 Characterization, isolation, and culture of mouse and human spermatogonial stem cells. Journal of Cellular Physiology 229 407-413. (doi:10.1002/jcp.24471)

Hai Y, Hou J, Liu Y, Yang H, Li Z \& He Z 2014 The roles and regulation of Sertoli cells in fate determinations of spermatogonial stem cells and spermatogenesis. Seminars in Cell \& Developmental Biology 29 66-75. (doi:10.1016/j.semcdb.2014.04.007)

Hofmann MC, Braydich-Stolle L \& Dym M 2005 Isolation of male germ-line stem cells; influence of GDNF. Developmental Biology 279 114-124. (doi:10.1016/j.ydbio.2004.12.006)

Hou J, Yang S, Yang H, Liu Y, Hai Y, Chen Z, Guo Y, Gong Y, Gao WQ, Li $\mathbf{Z}$ et al. 2014 Generation of male differentiated germ cells from various types of stem cells. Reproduction 147 R179-R188. (doi:10.1530/REP-13-0649)

Ishii K, Kanatsu-Shinohara M, Toyokuni S \& Shinohara T 2012 FGF2 mediates mouse spermatogonial stem cell self-renewal via upregulation of Etv5 and Bcl6b through MAP2K1 activation. Development 139 1734-1743. (doi:10.1242/dev.076539)

Jijiwa M, Kawai K, Fukihara J, Nakamura A, Hasegawa M, Suzuki C, Sato T, Enomoto A, Asai N, Murakumo Y et al. 2008 GDNF-mediated signaling via RET tyrosine 1062 is essential for maintenance of spermatogonial stem cells. Genes to Cells 13 365-374. (doi:10.1111/j.1365-2443.2008. 01171.x)

Jing S, Wen D, Yu Y, Holst PL, Luo Y, Fang M, Tamir R, Antonio L, Hu Z, Cupples $\mathbf{R}$ et al. 1996 GDNF-induced activation of the ret protein tyrosine kinase is mediated by GDNFR- $\alpha$, a novel receptor for GDNF. Cell 85 1113-1124. (doi:10.1016/S0092-8674(00)81311-2)

Kanatsu-Shinohara M \& Shinohara T 2013 Spermatogonial stem cell selfrenewal and development. Annual Review of Cell and Developmental Biology 29 163-187. (doi:10.1146/annurev-cellbio-101512-122353)

Kanatsu-Shinohara M, Inoue K, Takashima S, Takehashi M, Ogonuki N, Morimoto H, Nagasawa T, Ogura A \& Shinohara T 2012 Reconstitution of mouse spermatogonial stem cell niches in culture. Cell Stem Cell 11 567-578. (doi:10.1016/j.stem.2012.06.011)
Kanatsu-Shinohara M, Onoyama I, Nakayama KI \& Shinohara T 2014 Skp1Cullin-F-box (SCF)-type ubiquitin ligase FBXW7 negatively regulates spermatogonial stem cell self-renewal. PNAS 111 8826-8831. (doi:10. 1073/pnas.1401837111)

Kim S, Bardwell VJ \& Zarkower D 2007 Cell type-autonomous and nonautonomous requirements for Dmrt1 in postnatal testis differentiation. Developmental Biology 307 314-327. (doi:10.1016/j.ydbio.2007.04. 046)

Kubota H, Avarbock MR \& Brinster RL 2004 Growth factors essential for self-renewal and expansion of mouse spermatogonial stem cells. PNAS 101 16489-16494. (doi:10.1073/pnas.0407063101)

Lamberti D \& Vicini E 2014 Promoter analysis of the gene encoding GDNF in murine Sertoli cells. Molecular and Cellular Endocrinology 394 105-114. (doi:10.1016/j.mce.2014.07.006)

Lee J, Iwai T, Yokota T \& Yamashita M 2003 Temporally and spatially selective loss of Rec8 protein from meiotic chromosomes during mammalian meiosis. Journal of Cell Science 116 2781-2790. (doi:10. 1242/jcs.00495)

Lee J, Kanatsu-Shinohara M, Inoue K, Ogonuki N, Miki H, Toyokuni S, Kimura T, Nakano T, Ogura A \& Shinohara T 2007 Akt mediates selfrenewal division of mouse spermatogonial stem cells. Development 134 1853-1859. (doi:10.1242/dev.003004)

Lee J, Kanatsu-Shinohara M, Morimoto H, Kazuki Y, Takashima S, Oshimura M, Toyokuni S \& Shinohara T 2009 Genetic reconstruction of mouse spermatogonial stem cell self-renewal in vitro by Rascyclin D2 activation. Cell Stem Cell 5 76-86. (doi:10.1016/j.stem. 2009.04.020)

Li A, Eirin-Lopez JM \& Ausio J 2005 H2AX: tailoring histone H2A for chromatin-dependent genomic integrity. Biochemistry and Cell Biology 83 505-515. (doi:10.1139/o05-114)

Li XX, Chen SR, Shen B, Yang JL, Ji SY, Wen Q, Zheng QS, Li L, Zhang J, Hu ZY et al. 2013 The heat-induced reversible change in the blood-testis barrier (BTB) is regulated by the androgen receptor (AR) via the partitioning-defective protein (Par) polarity complex in the mouse. Biology of Reproduction 89 12. (doi:10.1095/biolreprod.113.109405)

Liao HF, Chen WS, Chen YH, Kao TH, Tseng YT, Lee CY, Chiu YC, Lee PL, Lin QJ, Ching YH et al. 2014 DNMT3 L promotes quiescence in postnatal spermatogonial progenitor cells. Development 141 2402-2413. (doi:10. 1242/dev.105130)

Lue Y, Wang C, Liu YX, Hikim AP, Zhang XS, Ng CM, Hu ZY, Li YC, Leung A \& Swerdloff RS 2006 Transient testicular warming enhances the suppressive effect of testosterone on spermatogenesis in adult cynomolgus monkeys (Macaca fascicularis). Journal of Clinical Endocrinology and Metabolism 91 539-545. (doi:10.1210/jc.2005-1808)

Mark M, Jacobs H, Oulad-Abdelghani M, Dennefeld C, Feret B, Vernet N, Codreanu CA, Chambon P \& Ghyselinck NB 2008 STRA8-deficient, spermatocytes initiate, but fail to complete, meiosis and undergo premature chromosome condensation. Journal of Cell Science $\mathbf{1 2 1}$ 3233-3242. (doi:10.1242/jcs.035071)

Mclver SC, Loveland KL, Roman SD, Nixon B, Kitazawa R \& McLaughlin EA 2013 The chemokine CXCL12 and its receptor CXCR4 are implicated in human seminoma metastasis. Andrology 1 517-529. (doi:10.1111/j.2047-2927.2013.00081.x)

Meng X, Lindahl M, Hyvonen ME, Parvinen M, de Rooij DG, Hess MW, Raatikainen-Ahokas A, Sainio K, Rauvala H, Lakso M et al. 2000 Regulation of cell fate decision of undifferentiated spermatogonia by GDNF. Science 287 1489-1493. (doi:10.1126/science.287.5457.1489)

Mirzapour T, Movahedin M, Tengku Ibrahim TA, Koruji M, Haron AW, Nowroozi MR \& Rafieian SH 2012 Effects of basic fibroblast growth factor and leukaemia inhibitory factor on proliferation and short-term culture of human spermatogonial stem cells. Andrologia 44 (Suppl 1) 41-55. (doi:10.1111/j.1439-0272.2010.01135.x)

Naughton CK, Jain S, Strickland AM, Gupta A \& Milbrandt J 2006 Glial cell-line derived neurotrophic factor-mediated RET signaling regulates spermatogonial stem cell fate. Biology of Reproduction 74 314-321. (doi:10.1095/biolreprod.105.047365)

Niu Z, Goodyear SM, Rao S, Wu X, Tobias JW, Avarbock MR \& Brinster RL 2011 MicroRNA-21 regulates the self-renewal of mouse spermatogonial stem cells. PNAS 108 12740-12745. (doi:10.1073/pnas.1109987108)

Oatley JM, Avarbock MR, Telaranta AI, Fearon DT \& Brinster RL 2006 Identifying genes important for spermatogonial stem cell self-renewal and survival. PNAS 103 9524-9529. (doi:10.1073/pnas.0603332103) 
Oatley JM, Avarbock MR \& Brinster RL 2007 Glial cell line-derived neurotrophic factor regulation of genes essential for self-renewal of mouse spermatogonial stem cells is dependent on Src family kinase signaling. Journal of Biological Chemistry 282 25842-25851. (doi:10. 1074/jbc.M703474200)

Oatley JM, Oatley MJ, Avarbock MR, Tobias JW \& Brinster RL 2009 Colony stimulating factor 1 is an extrinsic stimulator of mouse spermatogonial stem cell self-renewal. Development 136 1191-1199. (doi:10.1242/dev. 032243)

Oatley MJ, Kaucher AV, Racicot KE \& Oatley JM 2011 Inhibitor of DNA binding 4 is expressed selectively by single spermatogonia in the male germline and regulates the self-renewal of spermatogonial stem cells in mice. Biology of Reproduction 85 347-356. (doi:10.1095/biolreprod. 111.091330)

Paul C, Teng S \& Saunders PT 2009 A single, mild, transient scrotal heat stress causes hypoxia and oxidative stress in mouse testes, which induces germ cell death. Biology of Reproduction 80 913-919. (doi:10.1095/ biolreprod.108.071779)

Pawlowski WP \& Cande WZ 2005 Coordinating the events of the meiotic prophase. Trends in Cell Biology 15 674-681. (doi:10.1016/j.tcb.2005. 10.005)

Payne CJ, Gallagher SJ, Foreman O, Dannenberg JH, Depinho RA \& Braun RE 2010 Sin3a is required by Sertoli cells to establish a niche for undifferentiated spermatogonia, germ cell tumors, and spermatid elongation. Stem Cells 28 1424-1434. (doi:10.1002/stem.464)

de Rooij DG 2001 Proliferation and differentiation of spermatogonial stem cells. Reproduction 121 347-354. (doi:10.1530/rep.0.1210347)

Rossi P \& Dolci S 2013 Paracrine mechanisms involved in the control of early stages of mammalian spermatogenesis. Frontiers in Endocrinology 4 181. (doi:10.3389/fendo.2013.00181)

Sachs C, Robinson BD, Andres Martin L, Webster T, Gilbert M, Lo HY, Rafii S, Ng CK \& Seandel M 2014 Evaluation of candidate spermatogonial markers ID4 and GPR125 in testes of adult human cadaveric organ donors. Andrology 2 607-614. (doi:10.1111/j.2047-2927.2014.00226.x)

Simon L, Ekman GC, Garcia T, Carnes K, Zhang Z, Murphy T, Murphy KM, Hess RA, Cooke PS \& Hofmann MC 2010 ETV5 regulates Sertoli cell chemokines involved in mouse stem/progenitor spermatogonia maintenance. Stem Cells 28 1882-1892. (doi:10.1002/stem.508)

Song HW \& Wilkinson MF 2014 Transcriptional control of spermatogonial maintenance and differentiation. Seminars in Cell \& Developmental Biology 30 14-26. (doi:10.1016/j.semcdb.2014.02.005)

Suzuki H, Sada A, Yoshida S \& Saga Y 2009 The heterogeneity of spermatogonia is revealed by their topology and expression of marker proteins including the germ cell-specific proteins Nanos2 and Nanos3. Developmental Biology 336 222-231. (doi:10.1016/j.ydbio. 2009.10.002)

Suzuki H, Ahn HW, Chu T, Bowden W, Gassei K, Orwig K \& Rajkovic A 2012 SOHLH1 and SOHLH2 coordinate spermatogonial differentiation. Developmental Biology 361 301-312. (doi:10.1016/j.ydbio.2011. 10.027)

Tokuda M, Kadokawa Y, Kurahashi H \& Marunouchi T 2007 CDH1 is a specific marker for undifferentiated spermatogonia in mouse testes. Biology of Reproduction 76 130-141. (doi:10.1095/biolreprod.106. 053181)

Tsai MY, Yeh SD, Wang RS, Yeh S, Zhang C, Lin HY, Tzeng CR \& Chang C 2006 Differential effects of spermatogenesis and fertility in mice lacking androgen receptor in individual testis cells. PNAS 103 18975-18980. (doi:10.1073/pnas.0608565103) (doi:10.1073/pnas.0608565103)

Tyagi G, Carnes K, Morrow C, Kostereva NV, Ekman GC, Meling DD, Hostetler C, Griswold M, Murphy KM, Hess RA et al. 2009 Loss of Etv5 decreases proliferation and RET levels in neonatal mouse testicular germ cells and causes an abnormal first wave of spermatogenesis. Biology of Reproduction 81 258-266. (doi:10.1095/biolreprod.108.075200)

Wang RS, Yeh S, Tzeng CR \& Chang C 2009 Androgen receptor roles in spermatogenesis and fertility: lessons from testicular cell-specific androgen receptor knockout mice. Endocrine Reviews 30 119-132. (doi:10.1210/er.2008-0025)

Wu X, Schmidt JA, Avarbock MR, Tobias JW, Carlson CA, Kolon TF, Ginsberg JP \& Brinster RL 2009 Prepubertal human spermatogonia and mouse gonocytes share conserved gene expression of germline stem cell regulatory molecules. PNAS 106 21672-21677. (doi:10.1073/pnas. 0912432106)

Wu X, Oatley JM, Oatley MJ, Kaucher AV, Avarbock MR \& Brinster RL 2010 The POU domain transcription factor POU3F1 is an important intrinsic regulator of GDNF-induced survival and self-renewal of mouse spermatogonial stem cells. Biology of Reproduction 82 1103-1111. (doi:10.1095/biolreprod.109.083097)

Wu X, Goodyear SM, Tobias JW, Avarbock MR \& Brinster RL 2011 Spermatogonial stem cell self-renewal requires ETV5-mediated downstream activation of Brachyury in mice. Biology of Reproduction $\mathbf{8 5}$ 1114-1123. (doi:10.1095/biolreprod.111.091793)

Wu RC, Jiang M, Beaudet AL \& Wu MY 2013 ARID4A and ARID4B regulate male fertility, a functional link to the $A R$ and RB pathways. PNAS 110 4616-4621. (doi:10.1073/pnas.1218318110)

Yang QE, Kim D, Kaucher A, Oatley MJ \& Oatley JM 2013 CXCL12-CXCR4 signaling is required for the maintenance of mouse spermatogonial stem cells. Journal of Cell Science 126 1009-1020. (doi:10.1242/jcs.119826)

Yang S, Ping P, Ma M, Li P, Tian R, Yang H, Liu Y, Gong Y, Zhang Z, Li Z et al. 2014 Generation of haploid spermatids with fertilization and development capacity from human spermatogonial stem cells of cryptorchid patients. Stem Cell Reports 3 663-675. (doi:10.1016/j.stemcr.2014. 08.004)

Yeh JR, Zhang X \& Nagano MC 2011 Wnt5a is a cell-extrinsic factor that supports self-renewal of mouse spermatogonial stem cells. Journal of Cell Science 124 2357-2366. (doi:10.1242/jcs.080903)

Yoshida S, Takakura A, Ohbo K, Abe K, Wakabayashi J, Yamamoto M, Suda T \& Nabeshima Y 2004 Neurogenin3 delineates the earliest stages of spermatogenesis in the mouse testis. Developmental Biology 269 447-458. (doi:10.1016/j.ydbio.2004.01.036)

Yoshida S, Sukeno M \& Nabeshima Y 2007 A vasculature-associated niche for undifferentiated spermatogonia in the mouse testis. Science $\mathbf{3 1 7}$ 1722-1726. (doi:10.1126/science.1144885)

Yoshinaga K, Nishikawa S, Ogawa M, Hayashi S, Kunisada T \& Fujimoto T 1991 Role of $\mathrm{c}$-kit in mouse spermatogenesis: identification of spermatogonia as a specific site of c-kit expression and function. Development 113 689-699.

Zhang XS, Zhang ZH, Jin X, Wei P, Hu XQ, Chen M, Lu CL, Lue YH, Hu ZY, Sinha Hikim AP et al. 2006 Dedifferentiation of adult monkey Sertoli cells through activation of extracellularly regulated kinase 1/2 induced by heat treatment. Endocrinology 147 1237-1245. (doi:10.1210/en. 2005-0981)

Zhang J, Eto K, Honmyou A, Nakao K, Kiyonari H \& Abe S 2011 Neuregulins are essential for spermatogonial proliferation and meiotic initiation in neonatal mouse testis. Development 138 3159-3168. (doi:10.1242/dev.062380)

Zhang Y, Wang S, Wang X, Liao S, Wu Y \& Han C 2012 Endogenously produced FGF2 is essential for the survival and proliferation of cultured mouse spermatogonial stem cells. Cell Research 22 773-776. (doi:10. 1038/cr.2012.17)

Zheng K, Wu X, Kaestner KH \& Wang PJ 2009 The pluripotency factor LIN28 marks undifferentiated spermatogonia in mouse. BMC Developmental Biology 9 38. (doi:10.1186/1471-213X-9-38)

Zheng QS, Wang XN, Wen Q, Zhang Y, Chen SR, Zhang J, Li XX, Sha RN, Hu ZY, Gao F et al. 2014 Wt1 deficiency causes undifferentiated spermatogonia accumulation and meiotic progression disruption in neonatal mice. Reproduction 147 45-52. (doi:10.1530/REP-13-0299)

Zhou Q, Nie R, Prins GS, Saunders PT, Katzenellenbogen BS \& Hess RA 2002 Localization of androgen and estrogen receptors in adult male mouse reproductive tract. Journal of Andrology 23 870-881. (doi:10.1002/j.1939-4640.2002.tb02345.x)

Received 15 September 2014

First decision 20 October 2014

Revised manuscript received 25 November 2014

Accepted 11 December 2014 